\title{
The labor-supply elasticity and borrowing constraints: Why estimates are biased*
}

\author{
SSE/EFI Working Paper Series in Economics and Finance \\ No. 480 \\ David Domeij and Martin Flodén ${ }^{* *}$
}

November 29, 2001

\begin{abstract}
The labor-supply elasticity is a central element in many macroeconomic models. We argue that assumptions underlying previous econometric estimates of the intertemporal labor supply elasticity are inconsistent with incomplete markets economies. In particular, if the econometrician ignores borrowing constraints, the elasticity will be biased downwards. Within our model, the bias may be up to 50 percent. We find a similar bias in PSID data.
\end{abstract}

JEL classification: C20; C50; E20; J22

Keywords: labor supply elasticity; intertemporal substitution; liquidity constraints

\footnotetext{
${ }^{*}$ We thank seminar participants at NYU, Sveriges Riksbank, the SED 2001 conference, and the Toulouse Seminar in Macroeconomics. Financial support from the Jan Wallander and Tom Hedelius Foundtion at Svenska Handelsbanken is gratefully acknowledged.

** Department of Economics, Stockholm School of Economics, Box 6501, SE-113 83 Stockholm, Sweden.david.domeij@hhs.se,martin.floden@hhs.se.
} 


\section{Introduction}

Because intertemporal substitution of labor is a central element in most models used by macroeconomists today (some version of the permanent-income hypothesis model with capital market imperfections), much research has been devoted to examining whether it is an important determinant of labor supply. ${ }^{1}$ If the intertemporal substitution is important for labor-leisure choices, we would observe that individuals expecting increases in the real wage work little today and more in the future. Using microdata on wages, hours worked and various household characteristics, most studies however find that expected changes in the real wage only lead to small changes in hours worked. For men, most estimates of the intertemporal labor-supply elasticity are in the range between 0 and 0.5 (see for example Heckman and MaCurdy 1980, MaCurdy 1981, Altonji 1986, Blundell and MaCurdy 1999).

The microeconomic evidence thus suggests that a low elasticity should be used in macroeconomic models. Browning et al. (1999), however, note that microeconomic estimates often are incompatible with macroeconomic models. In this paper, we argue along these lines that previous estimates of the labor-supply elasticity are indeed inconsistent with macroeconomic models with incomplete markets. In particular, if the econometrician ignores borrowing constraints, the elasticity will be biased downwards. ${ }^{2}$

The goal of this paper is to quantitatively assess this bias. We do this by first applying standard econometric methods on synthetic data generated from a macroeconomic model in which we know the true labor-supply elasticity. ${ }^{3}$ We then estimate the elasticity using data from the Panel Study of Income Dynamics (PSID), with and without instruments for borrowing constraints.

\footnotetext{
1 The classical article emphasizing the role of intertemporal labor supply is Lucas and Rapping (1969).

2 A large fraction of U.S. households hold virtually no wealth and many households do not even have a bank or checking account (see Deaton 1991 and Diaz-Gimenez et al. 1997). It seems unlikely that these households can use credit to smooth consumption. More direct evidence of liquidity constraints is reported by Japelli (1990) who found that approximately 20 percent of U.S. households are constrained.

3 Guvenen (2000) use a similar method to argue that estimates of the intertemporal elasticity of substitution are inconsistent with macroeconomic models, and that these estimates are biased downwards.
} 
In the next section, we introduce a model, developed by Huggett (1993), and Aiyagari (1994). This model has become the workhorse tool for analyzing economies with incomplete markets and household heterogeneity. The economy is populated by a large number of infinitely-lived households that face uninsurable idiosyncratic wage risk, supply labor elastically and trade a single asset. Each household can achieve a path for consumption that is smoother than its path for labor income by adjusting its asset holdings and its labor supply in response to wage shocks.

Households have an incentive to accumulate a buffer stock of savings when their labor income is above average, since borrowing is ruled out by assumption. Because wage shocks are uncorrelated across households, the distributions of income and wealth in the model are endogenous.

Section 3 outlines the most important estimation procedures that have been applied in the empirical literature. We also demonstrate how the presence of borrowing constraints affects the equations to be estimated, and why estimates of the elasticity may be downward biased if borrowing constraints are ignored.

In Section 4, we report the results of using these econometric methods to estimate the labor supply elasticity from data generated by the model. We find that the downward bias is around 50 percent. That is if the true labor supply elasticity is 1 , the econometrician would find a value of 0.5 .

In Section 5, we apply the same econometric methods on PSID data. We first replicate previous estimates of the labor-supply elasticity. We then show that if we control for borrowing constraints, the estimates rise as theory suggests. 


\section{The model}

Our economy is populated by a continuum of infinitely lived households, endowed with one unit of time which is divided between labor, $h$, and leisure, $l$. Households choose labor supply and consumption $c$ to maximize expected discounted utility

$$
U_{0}=\mathrm{E}_{0} \sum_{t=0}^{\infty} \beta^{t} u\left(c_{t}, h_{t}\right),
$$

where $\beta$ is the subjective discount factor. Let $a_{t}$ denote a household's assets in the beginning of period $t$. We assume that households are unable to borrow, i.e.,

$$
a_{t} \geq 0
$$

Let $r_{t}$ denote the real return at date $t$ to one unit of the asset purchased at $t-1$ and let $w$ denote the real return to supplying one unit of effective labor. The household's budget constraint in period $t$ is then given by

$$
c_{t}+a_{t+1}=\left(1+r_{t}\right) a_{t}+w_{t} e_{t} h_{t} .
$$

where $e$ denotes the household's productivity, which evolves through time according to a first-order Markov chain. We normalize productivity to unity so that $\mathrm{E}(e)=1$. The timing convention is that $e_{t}$ is observed before decisions are made in period $t$, and we assume that there is no aggregate uncertainty.

Aggregate per capita output, $Y$, is produced according to a Cobb-Douglas technology

$$
Y_{t}=K_{t}^{\theta} H_{t}^{1-\theta}
$$

where $K$ and $H$ denote the aggregate capital stock and the aggregate effective labor supply. Output can be transformed into future capital and consumption according to

$$
C_{t}+K_{t+1}-(1-\delta) K_{t}=Y_{t}
$$


where $\delta$ is the rate of depreciation. Product and factor markets are assumed to be competitive, which implies that the real return to saving and the wage rate are given by

$$
r_{t}=\theta K_{t}^{\theta-1} H_{t}^{1-\theta}-\delta
$$

and

$$
w_{t}=(1-\theta) K_{t}^{\theta} H_{t}^{-\theta}
$$

We focus on stationary equilibria only. See e.g. Aiyagari (1994) and Aiyagari and McGrattan (1998) for the precise definition of such equilibria. The most important features of the equilibrium are that (i) factor prices are constant since there is no aggregate uncertainty, (ii) decision rules for consumption and labor supply are time-invariant functions of the household's asset holdings and productivity, and (iii) aggregate savings and labor supply implied by the decision rules sum to the aggregate capital stock and aggregate labor supply. Note also that although aggregates (including the distribution of households in wage-wealth space) are constant, there are fluctuations and uncertainty at the household level.

\subsection{Parameterization}

The model period is one year. All parameter values used are reported in yearly terms in table I. The parameters relating to aggregate production and preferences are set to standard values. The capital share in the production function is 0.3 and the depreciation rate is 0.075 . The discount factor $\beta$ is 0.95 .

We assume that logged productivity follows an $\mathrm{AR}(1)$ process with fixed effects

$$
\begin{aligned}
& \log e_{t}=\psi+z_{t} \\
& z_{t}=\rho z_{t-1}+\varepsilon_{t} .
\end{aligned}
$$


Various authors have estimated similar stochastic processes for logged labor productivity using data from the PSID. These processes can be summarized by $\rho, \sigma_{\varepsilon}$, and $\sigma_{\psi}$ - the serial correlation coefficient, the standard deviation of the innovation term $\varepsilon$, and the standard deviation of fixed effects $\psi$, respectively. Allowing for the presence of measurement error and the effects of observable characteristics such as education and age, work by Card (1991), Hubbard, Skinner and Zeldes (1995), and Flodén and Lindé (1999) indicates a $\rho$ in the range 0.88 to 0.96 , and a $\sigma_{\varepsilon}$ in the range 0.12 to 0.25 . We adopt the estimates of Flodén and Lindé and use the parameter values $\left\{\rho, \sigma_{\varepsilon}, \sigma_{\psi}\right\}=\{0.90,0.21,0.34\} .{ }^{4}$

The utility function is specified below.

\section{Estimation procedure}

In this section we describe the standard estimation procedures used in the literature. ${ }^{5}$ These are based on first order conditions for household optimization. Additional assumptions such as separability of the utility function or an explicit functional form for the utility are then added in order to obtain equations that can be estimated.

The first order conditions for the household's utility maximization in this framework are

$$
\begin{gathered}
u_{c_{t}}=\lambda_{t} \\
\lambda_{t} w e_{t}=-u_{h_{t}} \\
\lambda_{t}-\phi_{t}=(1+r) \beta \mathrm{E}_{t} \lambda_{t+1}
\end{gathered}
$$

where $\lambda_{t}$ is the marginal utility of wealth in period $t$ and $\phi_{t}$ is the marginal utility of borrowing in period $t$. In principle we can use these conditions to estimate the household's willingness to intertemporally substitute. In practise, this may only be done if

\footnotetext{
${ }^{4}$ When solving the model, we approximate the productivity process by a discrete Markov process using seven grid points for $z$ and two grid points for $\psi$.

${ }^{5}$ See Blundell and MaCurdy 1999 for a more elaborate discussion.
} 
consumption and hours worked enter the instantaneous utility function in a tractable way.

Before turning to the details of the estimation procedures, it is important to specify exactly which labor-supply elasticity we intend to estimate. The Frisch (or constant marginal utility of wealth) labor-supply elasticity is defined as

$$
\left.\eta^{\lambda} \equiv \frac{d h}{d w} \frac{w}{h}\right|_{\lambda} .
$$

From the first order conditions (6) and (7), we get

$$
\eta^{\lambda}=\frac{u_{h}}{h u_{h h}-\frac{h u_{h c}^{2}}{u_{c c}}}
$$

This elasticity shows how labor supply responds to an intertemporal reallocation of wages that leaves marginal utility of wealth unaffected. As Blundell and MaCurdy (1999, p. 1595) point out, this 'is the correct elasticity for assessing the impact of wage changes through time on labor supply'.

\subsection{Estimation with separable utility}

To obtain tractable results, it is often assumed that utility is separable in consumption and leisure, and this assumption has frequently been employed in the empirical literature. As the starting point for our analysis, let us therefore assume that the instantaneous utility function is separable and more specifically

$$
u(c, h)=\frac{c^{1-\mu}}{1-\mu}-\alpha \frac{h^{1+1 / \gamma}}{1+1 / \gamma} .
$$

This specification of the utility function is convenient since $\gamma$ is the Frisch intertemporal elasticity of substitution, which we aim to estimate. Further, $\mu$ is the coefficient of relative risk aversion, and $\alpha$ is a parameter determining the level of labor supply. 
The first order conditions can, as a first order approximation, be rewritten into the following log-linear equations

$$
\begin{gathered}
\ln h_{t}=\text { constant }+\gamma\left[\ln w+\ln e_{t}+\ln \lambda_{t}\right], \\
\ln c_{t}=\text { constant }-\frac{1}{\mu} \ln \lambda_{t}, \\
\ln \lambda_{t}-\frac{\phi_{t}}{\lambda_{t}}=\ln \lambda_{t+1}+\ln \beta(1+r)-\xi_{t+1},
\end{gathered}
$$

where $\xi_{t+1}$ is the forecast error.

Let $\Delta x_{t+1}=x_{t+1}-x_{t}$. Equation (11) can then be written in first differences,

$$
\Delta \ln h_{t+1}=\text { constant }+\gamma \Delta \ln e_{t+1}-\frac{\gamma \phi_{t}}{\lambda_{t}}+\gamma \xi_{t+1}
$$

MaCurdy (1981) and Altonji (1986) estimate the Frisch intertemporal labor supply elasticity by regressing the difference on log-wages on the difference in log-hours worked,

$$
\Delta \ln h_{t+1}=\text { constant }+\gamma \Delta \ln e_{t+1}+\gamma \xi_{t+1}
$$

which follows from their assumption of perfect capital markets.

Note that expected future wage increases are positively correlated with the marginal utility of borrowing, $\phi$, and uncorrelated with the marginal utility of wealth, $\lambda$, as long as $\phi$ is non-zero. Consequently, the estimate of $\gamma$ will be biased downwards if the term $-\gamma \phi_{t} / \lambda_{t}$ is ignored.

The error term, $\xi$, also includes an approximation error due to the log-linearization of the first order conditions. Ludvigson and Paxson (2001) show that these approximation errors may cause substantial downward bias in estimates of other parameters derived from the Euler equation. The log-linearization works particularly poorly when decision rules are non-linear as they are in states where households are or are close to being borrowing constrained, something which will make this bias larger. The Appendix contains a more 
detailed description of this bias and shows how we, in the simulated data, can separate the bias from omitting $\phi / \lambda$ from the bias due to the log-linearization.

Even if we could ignore the liquidity constraints and the log-linearization bias, there are econometrical obstacles to estimating (15). The error term $\xi$ is correlated with the explanatory variable $\Delta \ln e .{ }^{6}$ Equation (15) is therefore estimated with instruments for the productivity changes. ${ }^{7}$ To instrument for $\Delta \ln e_{t+1}$ in our synthetical framework we use the mathematical expectation of $\Delta \ln e_{t+1}$ at time $t, \mathrm{E}_{t} \Delta \ln e_{t+1}$, which contains all information about the productivity change except what is contained in $\xi_{t+1}$. This approach is not feasible when using real world data, since then the true productivity process is unknown and the exact productivity levels, fixed effects, etc. are not observed.

Altonji used lagged wages and lagged wage changes to instrument for future wage changes. Note that with our productivity process,

$$
\Delta \ln e_{t+1}=z_{t+1}-z_{t}=(\rho-1) z_{t}+\varepsilon_{t+1}=(\rho-1)\left(\ln e_{t}-\psi\right)+\varepsilon_{t+1}
$$

This equation shows that $\ln e_{t}$ is correlated with the productivity change. Obviously $\ln e_{t}$ is uncorrelated with the error term $\xi_{t+1}$. A potential problem when using $\ln e_{t}$ as the instrument is that it is correlated with the fixed effect $\psi$. This motivates, as is sometimes done in the empirical literature, using additional household variables when estimating (16). In our model framework the results are not sensitive to the choice of instruments and we consequently only report results using the mathematical expectation. When using real world data, we follow Altonji and use various combinations of lagged wages and household characteristics.

An alternative procedure for estimating the elasticity is pursued in Altonji (1986). He

\footnotetext{
${ }^{6}$ An exception is when households know their wage one period ahead, which is assumed by MaCurdy and in some of Altonji's specifications. In our model the only innovation between periods is the shock to household productivity.

${ }^{7}$ Another reason to instrument for $\Delta \ln e$ is the occurance of measurement errors. MaCurdy used year dummies and individual specific information such as age and education as instruments. Altonji used two different wage series for each household.
} 
uses (12) to rewrite equation (11) in log-levels,

$$
\ln h_{t}=\text { constant }+\gamma \ln e_{t}-\frac{\gamma}{\mu} \ln c_{t},
$$

and uses data on hours worked, wages, and food consumption to estimate $\gamma^{8}$ The advantage with this procedure is that borrowing constraints do not enter this equation. However, the use of consumption data is problematic. It is difficult to find good microdata containing both total consumption and labor supply. The PSID, used by Altonji, contains food consumption and income data, but using food consumption as a proxy for total consumption requires that food consumption is sufficiently separable from other consumption goods in the utility function.

To handle participation constraints, some authors (e.g. Browning et al. 1985, and Blundell et al. 1993, 1998) have estimated semi-log equations of the form ${ }^{9}$

$$
\Delta h_{t+1}=\text { constant }+\gamma \Delta \ln e_{t+1}+\varepsilon_{t+1} .
$$

Again, a correlation between $\Delta \ln e_{t+1}$ and the error term is likely. We therefore instrument for $\Delta \ln e_{t+1}$ using its mathematical expectation. Blundell and MaCurdy (1999) point out that this equation cannot be derived from any standard utility function. Furthermore, we find (see below) that this formulation performs poorly on the synthetic data.

\subsection{Non-separable utility}

The assumption that preferences are separable in consumption and leisure is generally regarded as restrictive and possibly unrealistic. Quite naturally, therefore, attempts have been made to allow for more general preferences in the empirical literature. Altonji (1986) argues that adding cross-substitution terms to equations (11) and (12) results in an approximation of the log-linearized first order conditions. As long as measurement

\footnotetext{
${ }^{8}$ Browning et al. (1999, section 3.2.2) discuss a similar approach.

9 The participation constraint is never binding with the utility function in equation (10).
} 
errors are negligible, the elasticity can still be estimated from the difference form (as in equations 15 and 14). The log-level form (17) will, however, result in a biased estimate of the labor-supply elasticity.

It is not clear what restrictions on preferences are needed for Altonji's approximation to be valid. Blundell and MaCurdy (1999) indeed argue that estimating the Frisch elasticity is not possible unless preferences are separable.

Unless a specific functional form for preferences is assumed, it will be difficult to further assess this issue. Let us therefore also consider the Cobb-Douglas utility function that has been used frequently in the macroeconomic literature,

$$
u(c, h)=\frac{\left[c^{\alpha}(1-h)^{1-\alpha}\right]^{1-\mu}}{1-\mu} .
$$

For this utility function, we can derive the intertemporal elasticity of leisure as

$$
\eta^{l}=\frac{1-\alpha(1-\mu)}{\mu}
$$

The Frisch elasticity, $\eta^{\lambda}=\frac{1-h}{h} \eta^{l}$, then depends on each household's labor supply. If participation constraints and borrowing constraints are not binding, one can derive the following relationships ${ }^{10}$

$$
\Delta \ln \left(1-h_{t+1}\right)=\mathrm{constant}-\eta^{l} \Delta \ln e_{t+1}-\frac{\xi_{t+1}}{\mu}
$$

and

$$
\ln \left(1-h_{t}\right)=\text { constant }-\ln e_{t}+\ln c_{t} .
$$

If $\Delta \ln h_{t+1}$ is used on the left hand side of (19), there is no reason to expect that the Frisch elasticity for labor supply will be estimated. First, the change in log hours is not identical to the negative of changes in log leisure. Further, even if that were the case, the elasticity for leisure is different from the Frisch elasticity. Equation (20) shows that

\footnotetext{
10 See the Appendix for the expressions with constraints.
} 
the log-level equation, even if estimated on leisure, is not related to the intertemporal elasticity.

The straightforward approach for obtaining an estimate of the average labor supply elasticity is thus to estimate $\eta^{l}$ from (19) and multiply by average $(1-h) / h$ (see Heckman and MaCurdy 1980, Browning et al. 1999). One problem with this approach is to measure leisure in the data. ${ }^{11}$ Moreover, there will be a downward bias in the estimate of $\eta^{l}$ if borrowing constraints are binding but ignored. Finally, with the Cobb Douglas utility function, participation constraints will bind for households with much wealth and low wages. If participation constraints bind, equation (7) does not hold with equality and the estimate of $\eta^{l}$ from (19) will be biased. ${ }^{12}$ In empirical work households with no or low labor supply are often excluded. Since $h_{t+1}$ is correlated with the wage change, that procedure may still induce a bias in the estimates.

\section{Estimation on synthetic data}

Tables II and III report estimation results based on the utility function specified in (10). As the benchmark, we have used the parameter values $\mu=2$ and $\gamma=1$ for the risk aversion and labor-supply elasticity, respectively.

Table II shows results from estimations of (15) on data generated by the model. The first column reports regression results for the full sample, thus ignoring borrowing constraints captured by $\phi$. The estimated elasticity is then 0.55 (recall that the true elasticity is unity). To control for borrowing constraints, we excluded households that choose to

\footnotetext{
${ }^{11}$ Heckman \& MaCurdy (1980) found that the estimates for $\eta^{l}$ (around 0.4 in their study) were not sensitive to the assumption of total available time. However, the ratio (total time $-h$ ) $/ h$ is sensitive to that assumption. If available time is 8760 hours ( 24 hours per day), the ratio is 5.5, but if instead available time is 5000 hours, the ratio falls to 2.7 . The implied labor supply elasticities are 2.2 and 1.1 respectively. According to Browning et al. (1999), the ratio is 4 and the implied Frisch elasticity is 1.6.

12 Our simulations show that participation constraints may be important. For example, estimates of (20) are biased downwards by 15 percent. When using the difference form in (19), the bias due to participation constraints in periods $t$ and $t+1$ almost cancel.
} 
hold no wealth. The estimate is then much closer to unity (see column 2). ${ }^{13}$ A further confirmation that the borrowing constrained households cause the downward bias in the estimate is evident from the third column. Only the households with no wealth were included in that regression, which shows a negative labor-supply response to wage increases.

Figure 1 is useful for understanding this bias. The figure shows labor supply decisions as a function of the current wage (productivity) and wealth. ${ }^{14}$ In a model with no borrowing constraints, households would choose to work hard in periods with high wages and to consume more leisure when wages are low. Here, however, the top lines in the figure show that labor supply is falling in the wage rate for households with little wealth and low wages. These households are (or are close to being) borrowing constrained. They would consequently have to reduce consumption drastically if they did not increase labor supply in response to falling wages. This kind of behavior is only quantitatively important for our estimations if it is displayed by a substantial fraction of households in the economy. The figure also plots the wealth-productivity distribution of households in the model economy. It is clear that many households are in regions where labor supply is flat or even falling in the wage rate.

Even though our model is simplistic, it fairly well captures the correlations between earnings and wealth, and between disposable income and wealth (0.15 and 0.29 in the model and 0.23 and 0.32 in the data). However, the model does not exactly match the wealth distribution observed in the data. In particular, the model generates too little wealth inequality. The Gini coefficient for wealth is 0.58 in the model and 0.78 in U.S.

\footnotetext{
13 The estimate is still less than unity because of the approximation error associated with log linearization. The approximation bias is closely related to liquidity constraints as households with little wealth have non-linear decision rules. Consequently, this approximation bias is negligible when only wealthy households are included (see column 4). The Appendix shows how to separate the direct bias stemming from liquidity constraints from the approximation bias. According to our calculations for the full-sample estimation, the direct effect accounts for 44 percent of the bias.

14 The figure only shows decision rules for households with the high fixed effect. Decison rules for households with the low fixed effect are similar.
} 
data, the bottom 40 percent in the wealth distribution hold 4.8 percent of assets in the model and 1.4 percent in data, and the top one percent hold 6 percent in the model and 29 percent in the data (U.S. data based on Diaz-Gimenez et al. 1997). The number of borrowing constrained households thus appears to be underpredicted by the model, indicating that the bias we find is not overstated.

Table III reports estimates of the semi-log specification in equation (18). As expected, the labor-supply elasticity is poorly estimated even when the borrowing constrained households are excluded.

The results using the Cobb-Douglas utility function (see Table IV) reconfirm the results above. With our specification, the true elasticity of leisure is 0.56 , while our estimate on the full sample is 0.43 . If households with little wealth and households with low labor supply are excluded, we obtain estimates close to the true elasticity. ${ }^{15}$

To investigate how robust the results are to our assumptions we have re-estimated the labor-supply elasticity on data generated under various model specifications. First, we solved the model for different labor-supply elasticities, $\gamma$. The bias due to ignoring borrowing constraints is around 50 percent independent of the size of the true labor elasticity.

Second, we considered a higher coefficient for risk aversion $(\mu=3)$. This has two opposing effects. On the one hand households hold more precautionary wealth, so fewer households are constrained. This tends to reduce the bias. On the other hand, higher risk aversion increases households preference for consumption smoothing, thus making households with little wealth less willing to reduce labor supply as wages fall. In our experiments the second effect dominates, resulting in a somewhat larger bias.

Third, in real life a small fraction of households have negative net wealth (about

\footnotetext{
15 We have also ran regressions like (15) and (18) on the data generated by this model. The first regression yields estimates that appear related to the true elasticity, albeit clearly biased downwards. The latter regression yields estimates far from the true elasticity. As noted in the previous section, these regressions have no foundation in the model.
} 
3 percent in U.S. data, see Diaz-Gimenez et al. 1997). We therefore relaxed the noborrowing assumption and let households borrow up to 150 percent of output per capita. This results in fewer households being constrained but there is still a 30 percent bias in the estimated labor-supply elasticity.

Finally, there is some disagreement as to the persistence of household productivity shocks. We therefore solved the model with the less persistent productivity process assumed in Aiyagari and McGrattan (1998) $\left(\rho=0.6\right.$ and $\left.\sigma_{\varepsilon}=0.24\right) .{ }^{16}$ With this productivity process the bias is smaller since (unrealistically) few households hold little wealth. Moreover, much recent empirical work (see Browning et al. 1999 for a discussion and survey) rather indicates that the wage process is more persistent (possibly non-stationary) than the process we use.

\section{Estimation on PSID data}

The previous sections suggest that the labor-supply elasticity should be re-estimated with controls for borrowing constraints. To do this we need data on hours worked, wages, and wealth. In 1984 and 1989, the PSID contained a supplement on household wealth. The most prominent previous studies based on the PSID data set are MaCurdy (1981) and Altonji (1986). However, MaCurdy used data from 1967 to 1976 and Altonji from 1968 to 1981. To control for liquidity, we limit our study to using data from the periods 1983 to 1985 and 1988 to 1990 . In the 1984 and 1989 sample, households report asset holdings at the time of the interview (early 1984 and 1989) and income and hours worked during the preceding year (1983 and 1988). For example, we obtain $h_{83}, w_{83}^{*}, w_{83}^{* *}, a_{84}$, and some household characteristics from the 1984 sample. The first wage measure, $w^{*}$, is calculated as the household head's total labor income divided by total hours worked. The second

\footnotetext{
16 Their process was based on estimates in Heaton and Lucas (1996).
} 
wage measure, $w^{* *}$, is the reported hourly wage rate, which is only available for hourly rated workers. Wealth is measured as the net amount of liquid assets (bank accounts plus bonds and stocks minus 'other debts'). ${ }^{17}$

Note that, while the model makes no distinction between different forms of wealth, we use net liquid assets as the wealth measure. A large fraction of total wealth is housing (52 percent in our sample). A house is an illiquid asset with large transaction costs that limit its use in smoothing consumption. Angeletos et al. (2001) also show that within an overlapping generations economy, households use liquid wealth to buffer income shocks, and typically sell all their illiquid wealth in one transaction after age 70. This suggests that we should use liquid wealth rather than total wealth.

We use the same sample selection criteria as Altonji and consider men that are household heads and between the age 25 and $60 .{ }^{18}$ Assets and wages are deflated to 1983 prices using CPI. Moreover, observations are treated as missing if hours worked are zero or exceed 4860 , or if hours or wages change by a factor 2.5 or more. Further, we exclude individuals whose marital status has changed, or whose wife or main cohabitor has changed.

To estimate the Frisch elasticity $\gamma$, we follow Altonji and consider the difference specification,

$$
\Delta \ln h_{t+1}=\text { constant }+\gamma \Delta \ln w_{t+1}^{*}-\xi_{t+1}
$$

where we instrument for $\Delta \ln w_{t+1}^{*}$ using $\Delta \ln w_{t}^{* *}$ and $\ln w_{t}^{* *}$. The reason for using lagged $w^{* *}$ rather than lagged $w^{*}$ as instruments is to avoid a bias implied by measurement errors in the wage data (see Altonji for a further discussion).

The first stage regression is estimated as

\footnotetext{
17 'Other debts' mostly consists of credit card charges, student loans, medical or legal bills, and loans from relatives.

18 Altonji only considered married men. Because we are restricted to using data from two years only, we have few observations in our sample and we see no reason to exclude non-married men. Furthermore, the results are not very sensitive with respect to this sample criteria, see below. MaCurdy used similar selection criteria but limits his study to ages 25 to 57 .
} 


$$
\begin{array}{cccc}
\Delta \ln w_{t}^{*}= & 0.17+ & 0.25 \Delta \ln w_{t-1}^{* *}- & 0.02 \ln w_{t-1}^{* *} \\
& (0.13) & (0.05) & (0.02) \\
R^{2}=0.03 & F=11.6 & n=697
\end{array}
$$

The low $R^{2}$ value and high $\mathrm{F}$ value show that lagged wages have little but significant explanatory power for future wages. ${ }^{19}$

Table V reports results of the second stage regression. The first column reports regression results for the full sample, thus ignoring borrowing constraints captured by $\phi$. The estimated elasticity is then 0.07 which is close to what Altonji found when using these instruments (see his table 1, columns 5-8). ${ }^{20}$

We cannot directly observe who is borrowing constraint in the data. Arguably, a household with little liquid wealth relative to historical income is likely to be constrained. Our preferred indicator of borrowing constraints is liquid wealth being less than one monthly income, but we also use other cut-off levels, wealth in absolute levels, and total instead of liquid wealth. Column 4 in Table V presents the results for our preferred specification. It shows that the estimated elasticity increases to 0.42 when liquidity constrained households are excluded from the sample. The results are robust to other indicators using liquid wealth (see columns 2, 3 and 5). If we instead control for borrowing constraints using total wealth, the results are qualitatively the same though quantitatively not as striking (see columns 6-9). This is what our previous discussion suggested. The standard errors for the estimated elasticities are large and the differences between the different estimates are not significant.

Most previous studies have only considered married men. To investigate the sensitivity of this sample criteria we have estimated the labor supply elasticity excluding unmarried men from our sample. The estimated elasticities for married men are somewhat smaller

\footnotetext{
${ }^{19}$ The $R^{2}$ is similar to Altonji's and the parameter estimates have the same signs as his.

20 The reported regression corresponds to Altonji's column 5. We have also included age and year dummies as in Altonji's columns 6-8, and the results are unchanged.
} 
than for all men, but they are also estimated with a substantial downward bias (see Table VI columns 1-3).

We have also estimated the labor-supply elasticity including all households in the PSID, not just the original (representative) SRC sample. Comparing Tables V and VI we see that the results are not sensitive to the inclusion of these households.

MaCurdy and, in some specifications, Altonji used various household characteristics as instruments for future wages changes. To investigate the sensitivity of our results to the choice of instruments we have also, estimated the labor-supply elasticity using year dummies, age, age $^{2}$, education, education ${ }^{2}$, age $\times$ education, and age $\times$ education $^{2}$ as instruments. The results are presented in Table VII. Since we now do not use $w^{* *}$ as an instrument we can include households that do not report hourly wages. When we restrict the attention to the hourly rated workers, the first stage regressions are not significant (these results are not reported). When we do not control for the presence of borrowing constraints, the estimated elasticity is 0.30 . The magnitudes of our estimated parameter values and standard errors in the are similar to those estimated by MaCurdy and Altonji. ${ }^{21}$ When using liquid wealth to control for borrowing constraints our estimated elasticity falls to 0.24 (but when using total wealth, the estimate is 0.40 ). When including the non-SRC households, the elasticity is 0.46 in the full sample, and increases to 0.56 when we control for borrowing constraints using liquid wealth. ${ }^{22}$ It should be emphasized (as also Altonji remarks), that the first stage regression has little explanatory power when only household characteristics are used as instruments for the wage change. The results in the second stage are therefore unreliable.

In our discussion of non-separable utility functions we concluded that, at least if utility

\footnotetext{
21 MaCurdy's estimate of the elasticity is 0.23 with a standard error of 0.10 in the specification most similar to ours (his table 1, row 1). Altonji's estimate when instrumenting with household characteristics is 0.28 with a standard error of 0.13 .

${ }^{22}$ We have ran the same regressions for married men, but the first-stage equations are not significant and the results are not reported.
} 
takes the Cobb Douglas form, the appropriate method for obtaining an estimate of the labor supply elasticity is to first estimate the leisure elasticity $\eta^{l}$ from equation (19). Our estimates of $\eta^{l}$ have the same pattern as, and are consistent with, the estimated laborsupply elasticities reported in Table V. For example, when we assume that total time is 5000 hours in a year, the estimated $\eta^{l}$ is 0.18 in the full sample, and 0.30 when controlling for liquid wealth. To convert these values into labor supply elasticities, we multiply by 1.25, which is the average of $(5000-H) / H$. Interestingly, and contrary to Heckman and MaCurdy (1980), our implied estimates of the labor-supply elasticity are not sensitive to the assumption about the total available time.

\section{Concluding remarks}

We have argued that labor-supply estimates will be biased downward if liquidity constraints are ignored. By using standard econometric methods on simulated data, we have also demonstrated that this bias may be substantial. Finally, using PSID data on male labor supply we estimate higher elasticities when workers with little liquid wealth are excluded from the sample.

There is a vast literature trying to estimate the labor-supply elasticity with different methods, using different data sets, and obtaining a variety of estimates. We have chosen to contrast our results to MaCurdy's (1981) and Altonji's (1986) because they used the PSID data set which occasionally contains detailed wealth data, and because their papers were the first, and still are among the few, that explicitly focus on the intertemporal elasticity (rather than on some static elasticity). Our study suggests that allowing for liquidity constraints in other empirical frameworks could further enhance our understanding of the labor-supply elasticity. 


\section{Appendix A Log-linearization and approximation bias}

This appendix demonstrates how the log-linearization of the Euler equation (8) may create an additional bias.

Assuming rational expectations, the realized marginal utility is equal to the expected marginal utility plus a mean-zero forecast error $\varepsilon$,

$$
\lambda_{t+1}=\mathrm{E}_{t} \lambda_{t+1}+\varepsilon_{t+1}
$$

The Euler equation is then

$$
\lambda_{t}-\phi_{t}=\beta(1+r)\left(\lambda_{t+1}-\varepsilon_{t+1}\right) .
$$

Take logs and use a first order linear approximation on the left hand side and a second order approximation on the right hand side to obtain ${ }^{23}$

$$
\ln \lambda_{t}-\frac{\phi_{t}}{\lambda_{t}}=\ln \beta(1+r)+\ln \lambda_{t+1}-\frac{\varepsilon_{t+1}}{\lambda_{t+1}}+\frac{1}{2}\left(\frac{\varepsilon_{t+1}}{\lambda_{t+1}}\right)^{2} .
$$

We obtained equation (13) by defining $\xi_{t+1} \equiv \varepsilon_{t+1} / \lambda_{t+1}$, and by assuming that $\xi^{2}$ is small. If we do not ignore the second order term, equation (14) is

$$
\Delta \ln h_{t+1}=\text { constant }+\gamma \Delta \ln e_{t+1}-\frac{\gamma \phi_{t}}{\lambda_{t}}+\gamma \xi_{t+1}-\frac{\gamma \xi_{t+1}^{2}}{2}
$$

A bias in estimates of $\gamma$ based on equation (15) can arise either because of borrowing constraints ( $\phi$ ignored) or because of the approximation error ( $\xi^{2}$ ignored). Using our synthetic data, we can account for the sources of the bias.

It is straightforward to calculate simulated values for the marginal utility of consumption, $\lambda_{t}$, using simulated consumption data. We calculate the marginal utility of borrowing as a function of the household's state variables, $\Phi(e, a)$ as $\lambda-\beta(1+r) \mathrm{E}\left(\lambda^{\prime} \mid e, a\right)$ using the household's decision rules. We use simulated data on $e$ and $a$ to generate $\phi$ (we use

\footnotetext{
${ }^{23}$ We have checked numerically that higher order terms of $\phi$ and $\varepsilon$ are of little importance.
} 
linear approximations between grid points in $\Phi)$. The forecast errors $\varepsilon$ are then calculated as $\lambda^{\prime}-(\lambda-\phi) /[\beta(1+r)]$.

In practice when estimating (15), we instrument for the productivity change $\Delta \ln e_{t+1}$ with its expected value. Therefore, we also instrument for $\xi_{t+1}^{2}$ by regressing simulated $\xi_{t+1}^{2}$ on information available at date $t$.

Let $\hat{\gamma}$ denote the estimate of $\gamma$ based on equation (15). We then see that

$$
\mathrm{E} \hat{\gamma}=\gamma-\frac{\gamma \operatorname{cov}\left(\mathrm{E} \Delta \ln e^{\prime}, \frac{\phi}{\lambda}\right)}{\operatorname{var}\left(\mathrm{E} \Delta \ln e^{\prime}\right)}-\frac{\gamma \operatorname{cov}\left(\mathrm{E} \Delta \ln e^{\prime}, \mathrm{E} \xi^{\prime 2}\right)}{2 \operatorname{var}\left(\mathrm{E} \Delta \ln e^{\prime}\right)}
$$

By calculating these moments on the simulated data, we account for the sources of the bias in $\hat{\gamma}$.

With the Cobb-Douglas utility function one also needs to allow for participation constraints in (19). Similar calculations result in

$$
\Delta \ln l_{t+1}=\mathrm{constant}-\eta^{l} \Delta \ln e_{t+1}+\frac{\phi_{t}}{\mu \lambda_{t}}-\frac{\xi_{t+1}}{\mu}+\frac{\xi_{t+1}^{2}}{2 \mu}+\eta^{l} \zeta_{t}-\eta^{l} \zeta_{t+1}
$$

where $\zeta$ is the lagrange multiplier on the participation constraint. The bias can be separated by

$\mathrm{E} \hat{\eta}^{l}=\eta^{l}-\frac{\operatorname{cov}\left(\mathrm{E} \Delta \ln e^{\prime}, \frac{\phi}{\lambda}\right)}{\mu \operatorname{var}\left(\mathrm{E} \Delta \ln e^{\prime}\right)}-\frac{\operatorname{cov}\left(\mathrm{E} \Delta \ln e^{\prime}, \mathrm{E} \xi^{\prime 2}\right)}{2 \mu \operatorname{var}\left(\mathrm{E} \Delta \ln e^{\prime}\right)}-\frac{\eta^{l} \operatorname{cov}\left(\mathrm{E} \Delta \ln e^{\prime}, \zeta\right)}{\operatorname{var}\left(\mathrm{E} \Delta \ln e^{\prime}\right)}+\frac{\eta^{l} \operatorname{cov}\left(\mathrm{E} \Delta \ln e^{\prime}, \mathrm{E} \zeta^{\prime}\right)}{\operatorname{var}\left(\mathrm{E} \Delta \ln e^{\prime}\right)}$

In our simulations, the last two terms in the above equation tend to cancel. 


\section{References}

[1] Aiyagari, S. Rao, 1994, "Uninsured Idiosyncratic Risk and Aggregate Saving", Quarterly Journal of Economics 109(3), 659-684

[2] Aiyagari, S. Rao and Ellen R. McGrattan, 1998, "The Optimum Quantity of Debt", Journal of Monetary Economics 42, 447-469

[3] Altonji, 1986, "Intertemporal Substitution in Labor Supply: Evidence from Micro Data", Journal of Political Economy 94(2), S176-S215

[4] Angeletos, George-Marios, David Laibson, Andrea Repetto, Jeremy Tobacman and Stephen Weinberg, 2001, "The Hyperbolic Consumption Model: Calibration, Simulation, and Empirical Evaluation", Journal of Economic Perspectives 15(3), 47-68

[5] Blundell, Richard, and Thomas E. MaCurdy, 1999, "Labor Supply: A Review of Alternative Approaches", in Aschenfleter and Card (eds.), Handbook of Labor Economics 3A, Elsevier Science, Amsterdam

[6] Blundell, Richard, Costas Meghir, and Pedro Neves, 1993, "Labour Supply and Intertemporal Substitution", Journal of Econometrics 59, 137-160

[7] Blundell, Richard, Alan Duncan, and Costas Meghir, 1998, "Estimating Labor Supply Responses Using Tax Reforms", Econometrica 66(4), 827-861

[8] Browning, Martin, Angus Deaton, and Margaret Irish, 1985, "A Profitable Approach to Labor Supply and Commodity Demands over the Life-Cycle", Econometrica $\mathbf{5 3 ( 3 )}, 503-544$

[9] Browning, Martin, Lars P. Hansen, and James J. Heckman, 1999, "Micro Data and Genereal Equilibrium Models", in Taylor and Woodford (eds.), Handbook of Macroeconomics 1A, Elsevier Science, Amsterdam 
[10] Card, David, 1991, "Intertemporal Labor Supply: An Assessment", NBER Working Paper No. 3602

[11] Deaton, Angus, 1991, "Saving and Liquidity Constraints", Econometrica 59(5), $1221-1248$

[12] Flodén, Martin, and Jesper Lindé, 2001, "Idiosyncratic Risk in the US and Sweden: Is There a Role for Government Insurance?", Review of Economic Dynamics 4(2), 406-437

[13] Diaz-Gimenez, Javier, Vincenzo Quadrini, and Jose-Victor Rios-Rull, 1997, "Dimensions of Inequality: Facts on the U.S. Distributions of Earnings, Income, and Wealth", Federal Reserve Bank of Minneapolis Quarterly Review 21(2), 3-21

[14] Guvenen, Muhammet. 2000, "Mismeasurement of the Elasticity of Intertemporal Substitution: The Role of Limited Stock Market Participation", GSIA Working Paper 2000-E26, Carnegie Mellon University.

[15] Heaton, John and Deborah Lucas, 1996, "Evaluating the Effect of Incomplete Markets on Risk Sharing and Assets Pricing", Journal of Political Economy 104(3), 443-487.

[16] Heckman, James J., and Thomas E. MaCurdy, 1980, "A Life-Cycle Model of Female Labour Supply", Review of Economic Studies 47(1), 47-74

[17] Hubbard, R. Glenn, Jonathan Skinner, and Stephen P. Zeldes, 1995, "Precautionary Saving and Social Insurance", Journal of Political Economy 103(2), 360-399.

[18] Huggett, Mark, 1993, "The Risk-Free Rate in Heterogeneous-Agent IncompleteInsurance Economies", Journal of Economic Dynamics and Control 17, 953-970. 
[19] Jappelli, Tullio, "Who is Credit Constrained in the U.S. Economy?", Quarterly Journal of Economics 105(1), 219-234.

[20] Lucas, Robert E. Jr, and Leonard A. Rapping, 1969, "Real Wages, Employment and Inflation", Journal of Political Economy 77(5), 721-754

[21] Ludvigson, Sidney, and Christina H. Paxson, 2001, "Approximation Bias in Linearized Euler Equations", Review of Economics and Statistics 83(2), 242-256

[22] MaCurdy, Thomas E., 1981, "An Empirical Model of Labor Supply in a Life-Cycle Setting" Journal of Political Economy 89(6), 1059-1085

[23] Mulligan, Casey, 1998, "Substitution Over Time: Another Look at Life Cycle Labor Supply", NBER Macroeconomic Annual 13, 75-134 


\section{Table I}

Benchmark parameter values

\begin{tabular}{|c|c|c|c|c|}
\hline $\bar{\beta}$ & 0.950 & & & \\
\hline$\delta$ & 0.075 & & Separable utility & Cobb Douglas utility \\
\hline$\theta$ & 0.300 & $\mu$ & 2.00 & 3.56 \\
\hline$\gamma$ & 1.000 & $\alpha$ & 10.00 & 0.39 \\
\hline$\rho$ & 0.900 & & & \\
\hline$\sigma_{\varepsilon}$ & 0.210 & & & \\
\hline$\sigma_{\psi}$ & 0.340 & & & \\
\hline
\end{tabular}
is 2 , and $\alpha$ is chosen so that average labor supply is approximately 0.33 .

Table II

Labor supply estimates, separable utility and synthetic data

\begin{tabular}{|c|c|c|c|c|}
\hline & \multicolumn{4}{|c|}{ sample: households with assets, $a_{t+1}$, belonging to } \\
\hline & {$[0, \infty)$} & $(0, \infty)$ & {$[0,0.1 \bar{a})$} & {$[\bar{a}, \infty)$} \\
\hline \multirow[t]{2}{*}{$\varphi$} & 0.00 & 0.01 & 0.01 & 0.02 \\
\hline & $(0.00)$ & $(0.00)$ & $(0.00)$ & $(0.00)$ \\
\hline \multirow[t]{2}{*}{$\Delta \ln e$} & 0.55 & 0.89 & -0.12 & 1.00 \\
\hline & $(0.00)$ & $(0.00)$ & $(0.01)$ & $(0.01)$ \\
\hline$R^{2}$ & 0.10 & 0.19 & 0.01 & 0.13 \\
\hline \# obs. & 199400 & 169849 & 54635 & 66452 \\
\hline
\end{tabular}


Table III

Separable utility and synthetic data: semi-log specification

\begin{tabular}{lcccc}
\hline \multicolumn{5}{c}{ sample: households with assets, $a_{t+1}$, belonging to } \\
& {$[0, \infty)$} & $(0, \infty)$ & {$[0,0.1 \bar{a})$} & {$[\bar{a}, \infty)$} \\
\hline$\varphi$ & 0.00 & 0.00 & 0.01 & 0.01 \\
& $(0.00)$ & $(0.00)$ & $(0.00)$ & $(0.00)$ \\
$\Delta \ln e$ & & & \\
& 0.16 & 0.27 & -0.07 & 0.26 \\
& $(0.00)$ & $(0.00)$ & $(0.00)$ & $(0.00)$ \\
\hline$R^{2}$ & & & 0.15 \\
$\#$ obs. & 0.08 & 0.21 & 0.01 & 66452 \\
Note: This table shows results from estimation of $\Delta h_{t+1}=\varphi+\gamma \Delta \ln e_{t+1}-\xi_{t+1}$ & using $\mathrm{E}_{t} \Delta \ln e_{t+1}$ as \\
instrument. Standard errors in parenthesis.
\end{tabular}

Table IV

Cobb Douglas utility and synthetic data: estimates of $\eta^{l}$

\begin{tabular}{lcccc}
\hline \multicolumn{5}{c}{ sample: households with assets, $a_{t+1}$, belonging to } \\
& {$[0, \infty)$} & $(0, \infty)$ & {$[0,0.1 \bar{a})$} & {$[\bar{a}, \infty)$} \\
\hline$\varphi$ & 0.00 & 0.00 & 0.00 & -0.01 \\
& $(0.00)$ & $(0.00)$ & $(0.00)$ & $(0.00)$ \\
$\Delta \ln e$ & 0.43 & 0.50 & 0.22 & 0.54 \\
& $(0.00)$ & $(0.00)$ & $(0.00)$ & $(0.01)$ \\
& & & & \\
\hline$R^{2}$ & 0.09 & 0.10 & 0.05 & 0.09 \\
$\#$ obs. & 199400 & 182763 & 40046 & 66318 \\
\hline
\end{tabular}

Note: This table shows results from estimation of $\Delta\left(1-h_{t+1}\right)=\varphi-\eta^{l} \Delta \ln e_{t+1}-\xi_{t+1} \operatorname{using} \mathrm{E}_{t} \Delta \ln e_{t+1}$ as instruments The true $\eta^{l}$ is 0.561 . Non-working households have been excluded in all regressions. Standard errors in parenthesis. 
Table V

Labor supply estimates and PSID data

\begin{tabular}{|c|c|c|c|c|c|c|c|c|c|}
\hline & \multicolumn{9}{|c|}{ sample: wealth criterion } \\
\hline & \multirow[t]{2}{*}{ no } & \multicolumn{4}{|c|}{ liquid assets $>$} & \multicolumn{4}{|c|}{ total wealth $>$} \\
\hline & & 0 & $\frac{1}{2} i^{m}$ & $i^{m}$ & $\$ 1,000$ & 0 & $\frac{1}{2} i^{y}$ & $i^{y}$ & $\$ 12,000$ \\
\hline$\varphi$ & $\begin{array}{c}-0.01 \\
(0.01)\end{array}$ & $\begin{array}{c}-0.02 \\
(0.01)\end{array}$ & $\begin{array}{c}-0.03 \\
(0.01)\end{array}$ & $\begin{array}{c}-0.03 \\
(0.01)\end{array}$ & $\begin{array}{c}-0.02 \\
(0.01)\end{array}$ & $\begin{array}{c}-0.01 \\
(0.01)\end{array}$ & $\begin{array}{c}-0.02 \\
(0.01)\end{array}$ & $\begin{array}{c}-0.03 \\
(0.01)\end{array}$ & $\begin{array}{c}-0.01 \\
(0.01)\end{array}$ \\
\hline$\Delta \ln w^{*}$ & $\begin{array}{c}0.07 \\
(0.19)\end{array}$ & $\begin{array}{c}0.33 \\
(0.21)\end{array}$ & $\begin{array}{c}0.37 \\
(0.23)\end{array}$ & $\begin{array}{c}0.42 \\
(0.24)\end{array}$ & $\begin{array}{c}0.33 \\
(0.25)\end{array}$ & $\begin{array}{c}0.03 \\
(0.19)\end{array}$ & $\begin{array}{c}0.16 \\
(0.22)\end{array}$ & $\begin{array}{c}0.28 \\
(0.23)\end{array}$ & $\begin{array}{c}-0.17 \\
(0.21)\end{array}$ \\
\hline$\overline{R^{2}}$ & 0.00 & 0.01 & 0.01 & 0.01 & 0.00 & 0.00 & 0.00 & 0.00 & 0.00 \\
\hline F-stat & 0.12 & 2.46 & 2.53 & 2.92 & 1.76 & 0.02 & 0.53 & 1.48 & 0.64 \\
\hline \# obs. & 697 & 483 & 400 & 346 & 373 & 665 & 524 & 442 & 508 \\
\hline
\end{tabular}




\section{Table VI}

\section{Labor supply estimates and PSID data: other samples}

$\begin{array}{lccc}\begin{array}{l}\text { Married } \\ \text { Representative }\end{array} & \begin{array}{c}\text { yes } \\ \text { yes }\end{array} & \begin{array}{c}\text { no } \\ \text { no }\end{array} & \begin{array}{c}\text { yes } \\ \text { no }\end{array} \\ \text { 1st stage } R^{2} & 0.04 & 0.03 & 0.05 \\ \text { 1st stage F-stat } & 13.53 & 21.72 & 27.34\end{array}$

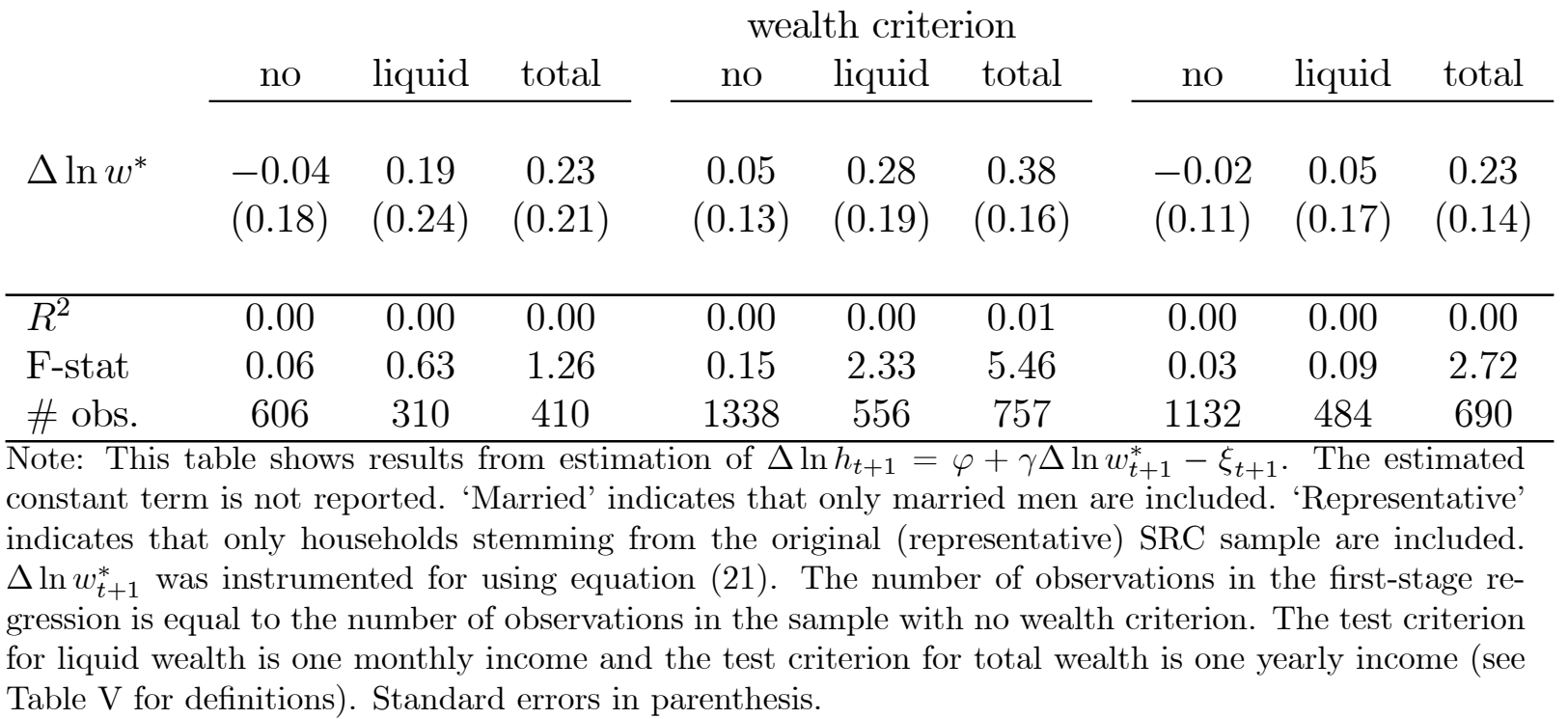


Table VII

Labor supply estimates and PSID data: other instrument

Representative

1st stage $R^{2}$

1st stage F-stat yes

0.01

2.81 no

0.00

2.02

\begin{tabular}{|c|c|c|c|c|c|c|}
\hline \multirow[b]{3}{*}{$\Delta \ln w^{*}$} & \multicolumn{6}{|c|}{ wealth criterion } \\
\hline & no & liquid & total & no & liquid & total \\
\hline & $\begin{array}{c}0.30 \\
(0.16)\end{array}$ & $\begin{array}{c}0.24 \\
(0.19)\end{array}$ & $\begin{array}{c}0.40 \\
(0.19)\end{array}$ & $\begin{array}{c}0.46 \\
(0.18)\end{array}$ & $\begin{array}{c}0.56 \\
(0.22)\end{array}$ & $\begin{array}{c}0.62 \\
(0.22)\end{array}$ \\
\hline$\overline{R^{2}}$ & 0.00 & 0.00 & 0.00 & 0.00 & 0.00 & 0.00 \\
\hline F-stat & 3.78 & 1.67 & 4.68 & 6.72 & 6.22 & 8.09 \\
\hline \# obs. & 2248 & 1361 & 1574 & 3596 & 1867 & 2248 \\
\hline
\end{tabular}

Note: This table shows results from estimation of $\Delta \ln h_{t+1}=\varphi+\gamma \Delta \ln w_{t+1}^{*}-\xi_{t+1}$. The estimated constant term is not reported. 'Representative' indicates that only households stemming from the original (representative) SRC sample are included. $\Delta \ln w_{t+1}^{*}$ was instrumented for using year dummies, age, age ${ }^{2}$, education, education ${ }^{2}$, age $\times$ education, and age $\times$ education $^{2}$. The number of observations in the first-stage regression is equal to the number of observations in the sample with no wealth criterion. The test criterion for liquid wealth is one monthly income and the test criterion for total wealth is one yearly income (see Table V for definitions). Standard errors in parenthesis. 


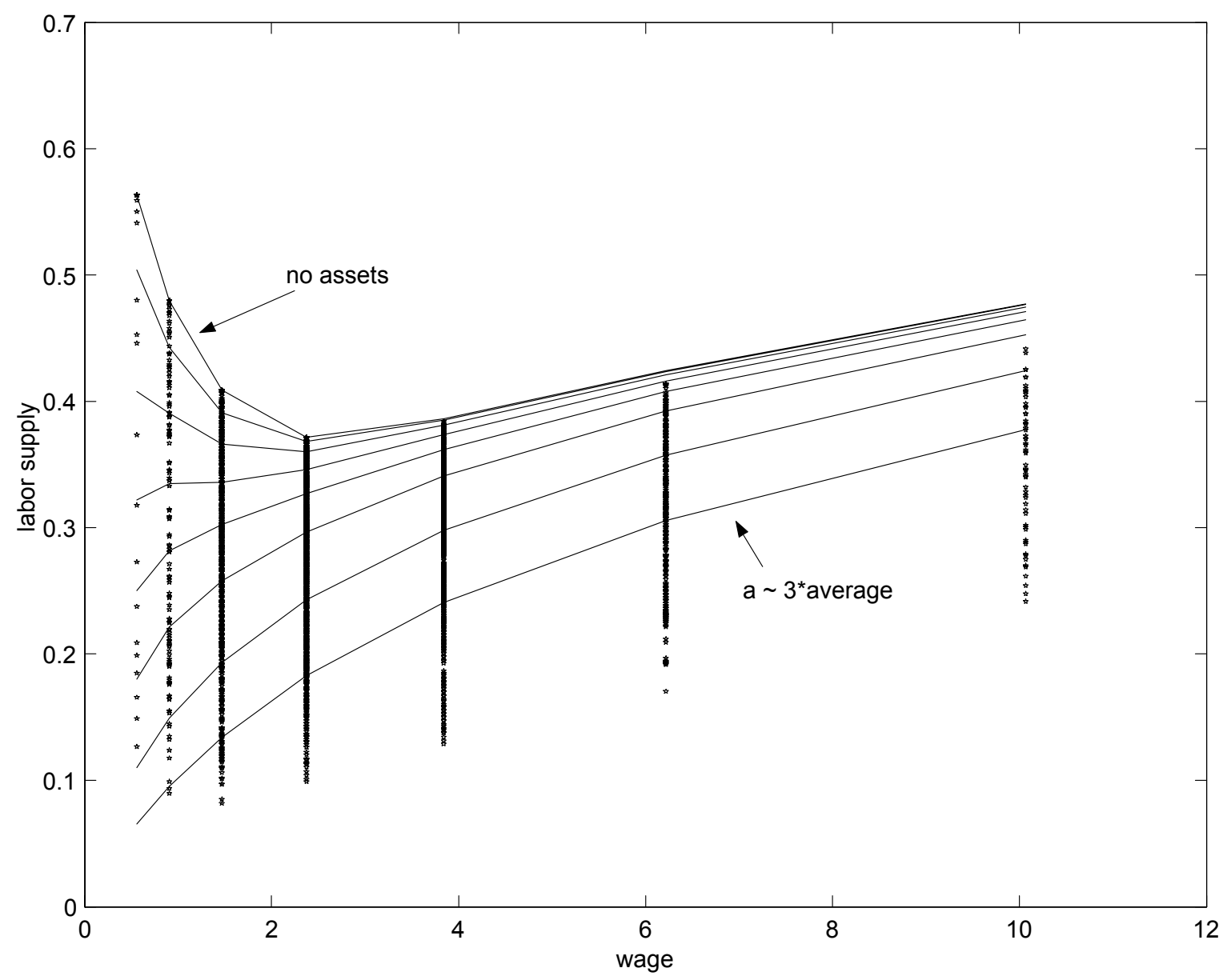

Figure 1: Decision rules for labor supply and distribution of households

The different lines represent labor supply decision rules for individuals with different wealth levels. Wealth increases from top to bottom. The top line shows labor supply decisions as a function of the idiosyncratic wage for a household with no wealth. The bottom line shows decision rules for a household with asset holdings three times as high as average asset holdings. The figure only displays decision rules for a few selected wealth levels. The dots indicate wage and labor combinations for a subsample of the simulated data. 